\title{
Role of the Host-Selective ACT-Toxin Synthesis Gene ACTTS2 Encoding an Enoyl-Reductase in Pathogenicity of the Tangerine Pathotype of Alternaria alternata
}

\author{
Naoya Ajiro, Yoko Miyamoto, Akira Masunaka, Takashi Tsuge, Mikihiro Yamamoto, Kouhei Ohtani, Takeshi Fukumoto, \\ Kenji Gomi, Tobin L. Peever, Yuriko Izumi, Yasuomi Tada, and Kazuya Akimitsu
}

First, second, third, sixth, seventh, eighth, tenth, eleventh, and twelfth authors: Faculty of Agriculture and Gene Research Center, Kagawa University, Miki, Kagawa 761-0795 Japan; fourth author: Graduate School of Bioagricultural Sciences, Nagoya University, Nagoya 4648601 Japan; fifth author: Faculty of Agriculture, Okayama University, Okayama 700-8530 Japan; and ninth author: Department of Plant Pathology, Washington State University, Pullman 99164-6430.

Accepted for publication 7 October 2009.

\begin{abstract}
Ajiro, N., Miyamoto, Y., Masunaka, A., Tsuge, T., Yamamoto, M., Ohtani, K., Fukumoto, T., Gomi, K., Peever, T. L., Izumi, Y., Tada, Y., and Akimitsu, K. 2010. Role of the host-selective ACT-toxin synthesis gene ACTTS2 encoding an enoyl-reductase in pathogenicity of the tangerine pathotype of Alternaria alternata. Phytopathology 100:120-126.

The tangerine pathotype of Alternaria alternata produces host-selective ACT-toxin and causes Alternaria brown spot disease of tangerines and tangerine hybrids. Sequence analysis of a genomic BAC clone identified a previously uncharacterized portion of the ACT-toxin biosynthesis gene cluster (ACTT). A 1,034-bp gene encoding a putative enoylreductase was identified by using rapid amplification of cDNA ends and
\end{abstract}

ABSTRACT

Seven strains of Alternaria alternata (Fr.) Keissl. are known to produce host-selective toxins (HST). HSTs produced by $A$. alternata are secondary metabolites with toxicity to specific plant genotypes and have the same specificity as infection by the toxinproducing pathogen $(28,33,38-40)$. These HST-producing strains are defined as distinct pathotypes of A. alternata $(18,28)$. The chemical structures of HSTs from six pathotypes have been elucidated (18), and several HST biosynthetic genes were recently cloned from the Japanese pear, strawberry, tangerine, rough lemon, tomato, and apple pathotypes $(1,2,6,7,10,11,20-23,30,35,36)$.

The tangerine pathotype of A. alternata causes Alternaria brown spot disease of many tangerines, mandarins, and their hybrids, and pathogenicity is dependent upon the production of ACT-toxin $(4,16,19)$. ACT-toxin is structurally related to AK- and AF-toxins, which are the HSTs produced by the Japanese pear and strawberry pathotypes of A. alternata, respectively $(4,24,25)$. These toxins share a common 9,10-epoxy-8-hydroxy-9-methyldecatrienoic acid moiety $(4,18,24,25)$. Three homologues (ACTT1, $A C T T 2$, and $A C T T R)$ of the $A K T 1, A K T 2$, and AKTTR genes carried by the Japanese pear pathotype are responsible for bio-

Corresponding author: K. Akimitsu; E-mail address: kazuya@ag.kagawa-u.ac.jp

Accession number for ACTTS2 sequence in DDBJ/GenBank is AB516322.

* The $\boldsymbol{e}$-Xtra logo stands for "electronic extra" and indicates that the online version contains a figure showing the sequence of ACTTS2 from the isolate $\mathrm{SH} 20$ of the tangerine pathotype of Alternaria alternata and a table showing the sequence of gene-specific primers used in this study. Figure 5 appears in color online.

doi:10.1094/PHYTO-100-2-0120

(C) 2010 The American Phytopathological Society polymerase chain reaction and designated ACTTS2. Genomic Southern blots demonstrated that ACTTS2 is present only in ACT-toxin producers and is carried on a $1.9 \mathrm{Mb}$ conditionally dispensable chromosome by the tangerine pathotype. Targeted gene disruption of ACTTS2 led to a reduction in ACT-toxin production and pathogenicity, and transcriptional knockdown of ACTTS2 using RNA silencing resulted in complete loss of ACT-toxin production and pathogenicity. These results indicate that ACTTS2 is an essential gene for ACT-toxin biosynthesis in the tangerine pathotype of A. alternata and is required for pathogenicity of this fungus.

Additional keywords: citrus, host-specific toxin, toxin biosynthesis gene cluster.

synthesis of the decatrienoic acid moiety in the tangerine pathotype (20-23,30,35,36). RNA silencing of the multicopy $A C T T 2$ encoding a hydrolase in the tangerine pathotype led to complete losses of the ACTT2 transcript, ACT-toxin production, and pathogenicity (23). ACTT5, encoding an acyl-CoA synthetase, and ACTT6, encoding an enoyl-CoA hydratase, were also identified by sequencing cosmid clone pcCL4-1 containing ACTT1, ACTT2, and ACTTR open reading frames (ORFs) (23). Targeted gene disruptions of two copies of ACTT5 significantly reduced ACT-toxin production and virulence, and targeted gene disruption of two copies of ACTT6 led to complete losses of ACTT6 transcription, ACT-toxin production, and pathogenicity (23).

In this study, we identified a previously uncharacterized region of genomic DNA from a BAC clone of A. alternata dual-pathotype isolate BC3-5-1-OS2A producing both ACT- and ACR-toxins (20) using ACTTR as a heterologous probe $(20,21)$. The genomic region contained several ORFs, and we report here the distribution and role in ACT-toxin production and the pathogenicity of one of these ORFs encoding a putative enoyl-reductase (1,034 bp) designated as ACTTS2.

\section{MATERIALS AND METHODS}

Plants and fungal strains. Young citrus leaves (midrib length 2 to $4 \mathrm{~cm}$ ) of cultivar Iyokan tangor (Citrus iyo hort. Ex Tanaka) grown in the greenhouse were used for inoculation and toxin sensitivity assays as described previously (20-23). Iyokan is susceptible to the tangerine pathotype of A. alternata and sensitive to ACT-toxin (16). Tangerine pathotype isolates SH11, 12, 13, $14,15,18,19,20,21$, and EV 10, 13, 14, 24, and rough lemon 
pathotype isolates $\mathrm{HC} 1, \mathrm{HC} 7, \mathrm{HC} 8, \mathrm{BC} 19, \mathrm{BC} 27$, and $\mathrm{BC} 35$ were obtained from leaf lesions of Minneola tangelo (Citrus reticulata Blanco $\times$ Citrus paradisi Macf.) and rough lemon in Florida for previous studies of the population structure and pathogenicity of Alternaria brown spot pathogen (20-23,29). Tangerine pathotype isolate $\mathrm{SH} 20$ has been used as the reference strain of Alternaria brown spot pathogen in previous studies (20-23). Isolates HC14, $\mathrm{BC} 17$, and $\mathrm{BC} 36$ are nonpathogenic strains of A. alternata sampled from rough lemon leaves $(21,29)$ and isolate BC3-5-1OS2A, a dual-pathotype strain producing both ACT-toxin and ACR-toxin (20), was also used in this study. In addition, laboratory stocks $(22,23)$ of Japanese pear pathotype isolates G31 and G90-A2, strawberry pathotype isolates NAF-3 and NAF-8, tomato pathotype isolates 91080804 and AL-4, apple pathotype isolates AM-1 and O-159, and tobacco pathotype isolates No. 122-2 and AT-204 were used in this study. Another nonpathogenic A. alternata isolate O-94 was obtained from H. Otani, Tottori University, Japan. All isolates including transformants of isolate $\mathrm{SH} 20$ were stored in $25 \%$ ( vol/vol) glycerol at $-85^{\circ} \mathrm{C}$, and cultures were initiated from the stocks for each experiment by growth on V8 juice agar or potato dextrose agar (PDA) plates.

Nucleic acid manipulations. Extraction of genomic DNA and total RNA, genomic polymerase chain reaction (PCR) and reverse transcription-PCR (RT-PCR) and Southern blot hybridizations using digoxigenin (DIG)-PCR labeled probes (Roche, Basel, Switzerland) were carried out as previously described $(9,12,13$, 20-23). Restriction enzyme digestion of genomic DNA $(5 \mu \mathrm{g})$, agarose gel electrophoresis, and capillary transfer were conducted under standard conditions (31). A BAC library was constructed from A. alternata dual-pathotype isolate BC3-5-1-OS2A (20). Genomic DNA fragments of approximately $100 \mathrm{~kb}$ from BC-3-51-OS2A separated by pulse field gel electrophoresis (PFGE) $(20,22,23)$ were ligated into the Bam HI site of a pcc1 BAC vector (Epicentre, Madison, WI). Ligated vector was introduced into $E$. coli (DH10B) (Invitrogen, San Diego, CA) by electroporation. After verifying the titer and length of insert, colonies screened by blue-white selection were randomly picked onto 384 wells plates (total of nine plates) and maintained as glycerol stocks. The genomic BAC library was screened by colony hybridization with a DIG-labeled ACTTR probe generated using primers ACTTRF1 (5'-CAACAGCAGTCGAACC-3') and ACTTRR1 (5'-CGTCTAGAACGAATCG-3') (e-Xtra), which were designed previously based on sequences from cosmid clone pcCL4-1 (AB176941) $(22,23)$. BAC DNA was extracted as described previously $(20,31)$, and the entire insert of $\mathrm{BAC}$ clone $2 \mathrm{H} 2$ was sequenced to $5 \times$ redundancy by shotgun sequencing using a capillary DNA sequencer. Transcripts of ACTTS2 were amplified with or without addition of reverse transcriptase (Takara) by RT-PCR using the following primer sets: 2H2C7F1 (5'-TGTTGACTCGTCGTGC$\left.3^{\prime}\right)$ and 2H2C7R2 (5'-TCCAGATAGCAGGCGA-3') for ACTTS2, and actinFor ( $5^{\prime}$-AGATGACACAGATTGTTTTCGAGACC- $3^{\prime}$ ) and actinRev (5'-AGTTGAAAGTGGTGACGTGGATACC-3') for the actin gene actl of A. alternata (AY748985), respectively (e-Xtra). RT-PCR products were transferred to Hybond- $\mathrm{N}^{+}$membranes using standard methods (31) and detected with DIG-labeled PCR amplicons of ACTTS2 probe by the method described previously $(9,12,13,20-23)$. Transcription initiation sites were identified with 2H2C7RACER1 (5'-CTTTGCTGTAACATAGGAGGCAAATCC$\left.3^{\prime}\right)$ and GeneRacer 5' Primer, and 2H2C7RACER2 (5'GATTTAGGGCTACAGCTTTGACTTTGAC-3') (e-Xtra) and GeneRacer 5' Nested Primer for nested PCR by 5' rapid amplification of cDNA ends (RACE) with the GeneRacer Kit (Invitrogen) according to the manufacturer's instructions. Transcription stop site was identified with 2H2C7RACEF1 (5'CGACAGGAACTCTAGCTGTACAATATGC-3') and GeneRacer 3' Primer, and 2H2C7RACEF2 (5'-GCTTTCTCTCGTCTTCGACACTATCTCT-3') (e-Xtra) and GeneRacer 3' Nested Primer for nested PCR by $3^{\prime}$ RACE. Amplicons were subcloned into
pT7Blue-2 vector (Novagen, Madison, WI) following the manufacturer's instructions. Sequencing was performed by the dideoxy chain termination method (32) using an ABI PRISM Dye Termination Cycle Sequencing Ready Reaction Kit (Applied Biosystems, Foster City, CA) and an automated fluorescent DNA sequencer (Model 310, Applied Biosystems). Sequence identities were estimated using FASTA searches at the DNA Data Bank of Japan (http://www.ddbj.nig.ac.jp), and domain and motif analysis were estimated using software at the Pfam (http://www. sanger.ac.uk/Software/Pfam/) (5).

Plasmid vector constructs and fungal transformation. Targeting vector pT7-ACTTS2 was constructed using a partial ACTTS2 sequence amplified by PCR consisting of 30 cycles (denaturing for $2 \mathrm{~min}$ at $95^{\circ} \mathrm{C}$, primer annealing for $1 \mathrm{~min}$ at $55^{\circ} \mathrm{C}$, and extension for $1 \mathrm{~min}$ at $72^{\circ} \mathrm{C}$ ) with the primer set 2H2C7F1 and 2H2C7R2 using genomic DNA of SH20 as the template. The partial ACTTS2 sequence amplified by PCR was subcloned into the EcoRV site of subcloning vector pT7Blue-2 (Novagen) and used as the targeting vector pT7-ACTTS2 for disruption of ACTTS2 using homologous recombination. The targeting vector was cotransformed with pSH75 (15) carrying $h p h$ cassette as a selection marker as described previously $(9,12$, $13,22,23)$.

For construction of the ACTTS2 RNA-silencing vector, senseand antisense-inserts of ACTTS2 were amplified from genomic DNA of SH20 by PCR consisting of 30 cycles (denaturing for 1 min at $95^{\circ} \mathrm{C}$, primer annealing for $1 \mathrm{~min}$ at $55^{\circ} \mathrm{C}$, and extension for $1 \mathrm{~min}$ at $72^{\circ} \mathrm{C}$ ) using a primer set of either $2 \mathrm{H} 2 \mathrm{C} 7 \mathrm{RiF} 3-2 \mathrm{Bg} I I \mathrm{I}$ (5'-GAAGATCTTCATCGATCTTGTACACCAAC-3') containing a BglII site and 2H2C7RiR3BglII (5'-GAAGATCTTCATGTTGACTCGTCGTGCTC-3') containing a BglII site, or 2H2C7RiF4NspV (5'-TTCGAAATGTTGACTCGTGCTC-3') containing an $N s p \mathrm{~V}$ site and 2H2C7RiR4-3NspV (5'-TTCGAAATCGATCTTGTACACCAAC- $3^{\prime}$ ) containing an $N s p \mathrm{~V}$ site (e-Xtra). PCR products (anti-sense ACTTS2) amplified with 2H2C7RiF3-2BglII and 2H2C7RiR3BglII digested with BglII and the RNA-silencing vector for Alternaria spp. (pASY) (23) digested with $B g l$ II following dephosphorylation with alkaline phosphatase (Takara, Shiga, Japan), were ligated at the region between the $\operatorname{trp} C$ promoter and the spacer region of pASY. PCR products (sense ACTTS2) amplified with $2 \mathrm{H} 2 \mathrm{C} 7 \mathrm{RiF} 4 \mathrm{NspV}$ and 2H2C7RiR4-3NspV digested with $N s p \mathrm{~V}$, and the pASY containing antisense ACTTS2 digested with $N s p \mathrm{~V}$ following dephosphorylation with alkaline phosphatase, were ligated at the region between the spacer region and $\operatorname{trpC}$ terminator. The vector construct of pASY-ACTTS2 for RNA-silencing of ACTTS2 was confirmed by PCR and sequencing using a primer set of PacCITF1multisite (5'-GAATTCTGCAGATATCAGATCTGTAAGTTGACCGCCAAG-3') designed from the spacer region in the internal vector construct and $2 \mathrm{H} 2 \mathrm{C} 7 \mathrm{RiR} 4-3 \mathrm{NspV}$ for sense insertion, or of PacCITR1multisite (5'-GAATTCAAGCTTTAAATTCGAACTGCAATCGAGTCAGC-3') and 2H2C7RiR3Bg1II for anti-sense insertion (e-Xtra).

Plasmid vector pAGY used for cotransformation with pASYACTTS2 was constructed in Alternaria overexpression vector pAOEIK (13) by insertion of NPTII gene amplified by PCR consisting of 30 cycles (denaturing for $1 \mathrm{~min}$ at $95^{\circ} \mathrm{C}$, primer annealing for $1 \mathrm{~min}$ at $55^{\circ} \mathrm{C}$, and extension for $1 \mathrm{~min}$ at $72^{\circ} \mathrm{C}$ ) with the primer set NPTIIF1EcoRI (5'-GGAATTCCATGATTGAACAAGATGGATTG-3') and NPTIIR1EcoRI (5'-GGAATTCCTCAGAAGAACTCGTCAAGAA-3') (e-Xtra) using the plasmid vector pII99 (26) as the template. The PCR amplicon and pAOEIK were digested with EcoRI, and the digested vector was dephosphorylation with alkaline phosphatase (Takara) following the ligation with the PCR product at the region between trpC promoter and trpC terminator to construct the NPTII cassette.

Protoplast preparation and transformation of isolate $\mathrm{SH} 20$ or its mutants were carried out using methods described previously 
$(9,12,13,22,23)$. Protoplasts $\left(1 \times 10^{7}\right)$ were transformed with $3 \mu \mathrm{g}$ of each vector. Colonies were transferred to PDA plates containing hygromycin $\mathrm{B}(50 \mu \mathrm{g} / \mathrm{ml})$ or geneticin $(200 \mu \mathrm{g} / \mathrm{ml})$ and grown at $24^{\circ} \mathrm{C}$ for 5 to 7 days and single spore cultures were recovered as described previously $(9,12,13,22,23)$.

Detection of plasmid integration, ACT-toxin production, and pathogenicity. Integration patterns of transformation vectors for targeted gene disruption were determined using genomic Southern blots probed with the ACTTS 2 probe. Integration of the RNA-silencing vector was determined using genomic Southern blots with DIG-labeled NTPII probe prepared by the primer set of NTPIIF1 (5'-ATGATTGAACAAGATGGATTG-3') and NTPIIR1 (5'-TCAGAAGAACTCGTCAAGAA-3'), and genomic PCR using a primer set of PacCITF1multisite and 2H2C7RiR4-3NspV (e-Xtra). Hybridization and detection were conducted as described previously $(9,12,13,20-23)$.

ACT-toxin production was quantified by placing dilute culture filtrates $\left(10^{1}\right.$ to $10^{3}$ in water) onto wounded sites of young leaves of Iyokan and Nijisseiki, as previously described (21-23). Sixtyone independent ACTTS2-silenced transformants were tested. Leaves were incubated in a moist chamber at $24^{\circ} \mathrm{C}$ in the dark, and necrosis development on the leaves was observed after $48 \mathrm{~h}$. Transformants causing less than 50\% necrosis compared with that caused by the wild type (isolate $\mathrm{SH} 20$ ) were further examined for the pathogenicity assay by inoculation tests and a high-pressure liquid chromatography (HPLC) analysis of ACT-toxin production. For HPLC examination of ACT-toxin production in culture filtrates, A. alternata strain SH20 and its mutants were grown in 200 - $\mathrm{ml}$ flasks containing $50 \mathrm{ml}$ of AC-toxin medium for 25 to 30 days at $24^{\circ} \mathrm{C}$. Extracts of culture filtrates $(50 \mathrm{ml})$ were prepared as described previously $(17,18,20-23)$, and resuspended in $1 \mathrm{ml}$ of methanol. Equal volume $(50 \mu \mathrm{l}$ from the extract solution in $1 \mathrm{ml}$ of methanol) of each sample was used for a further HPLC analysis and run for HPLC using a Model PU-2080 HPLC system (Japan Spectroscopic, Tokyo, Japan) with a Develosil ODS-5 column $(4.6 \times 250 \mathrm{~mm}$, NOMURA Chemical, Aichi, Japan) and a gradient solvent system composed of acetonitrile/water/acetic acid (linear gradient from 30:70:1 to 60:40:1, $\mathrm{vol} / \mathrm{vol} / \mathrm{vol}$ ) in $30 \mathrm{~min}$ at a flow rate of $1 \mathrm{ml} / \mathrm{min}$ with an absorbance at $290 \mathrm{~nm}$ was used as in the methods described previously $(17,18,20-23)$.

For pathogenicity assays, spores of each isolate were collected from mycelial mats grown in potato dextrose broth for 3 weeks and suspended in water at $1 \times 10^{5}$ spores $/ \mathrm{ml}$ and spray-inoculated on the lower surface of detached young leaves (midrib length 3.0 to $4.0 \mathrm{~cm}$ ) of ACT-toxin-sensitive citrus cultivar Iyokan as described previously (20-23). Leaves were incubated in a moist chamber for $48 \mathrm{~h}$ at $24^{\circ} \mathrm{C}$ in the dark, and the development of leaf spots and necrosis was monitored.

PFGE and hybridization. Preparation of fungal protoplasts for separation of chromosomes by PFGE and running conditions for PFGE were described previously (3,7,21-23). Running conditions (duration, voltage, linear gradient of switching time) in the PFGE apparatus (CHEF-DRII, Bio-Rad, Richmond, CA) consisted of $0.5 \times \mathrm{TBE}(31)$ at $8^{\circ} \mathrm{C}$ in $0.8 \%$ (wt/vol) agarose gel (Seakem Gold agarose; Cambrex BioScience Rockland, Inc., Rockland, ME), $25 \mathrm{~h} / 1.6 \mathrm{~V} / \mathrm{cm} / 500 \mathrm{~s}, 30 \mathrm{~h} / 1.6 \mathrm{~V} / \mathrm{cm} / 1,000 \mathrm{~s}$, and $50 \mathrm{~h} / 1.6 \mathrm{~V} / \mathrm{cm} / 1,500 \mathrm{~s}, 32 \mathrm{~h} / 1.6 \mathrm{~V} / \mathrm{cm} / 2,000 \mathrm{~s}$. Chromosomal DNA bands were visualized by ethidium bromide staining, and the gel was serially treated by soaking in $0.2 \mathrm{~N} \mathrm{HCl}$ for $20 \mathrm{~min}$ (to nick chromosomal DNA), $0.4 \mathrm{~N} \mathrm{NaOH}$ plus $1.5 \mathrm{M} \mathrm{NaCl}$ for $1 \mathrm{~h}$ to transfer Hybond- $\mathrm{N}^{+}$membrane (Amersham Biosciences, Piscataway, NJ) by alkaline capillary transfer (31) with $0.4 \mathrm{~N}$ $\mathrm{NaOH}$ and $1.5 \mathrm{M} \mathrm{NaCl}$ for $48 \mathrm{~h}$. The membrane was baked at $80^{\circ} \mathrm{C}$ for $2 \mathrm{~h}$ to fix the DNA and hybridized at $68^{\circ} \mathrm{C}$ overnight with ACTTS 2 probes. Hybridization and wash were conducted under high stringency conditions according to the manufacturer's instructions as described previously (20-23).

\section{RESULTS}

Identification and genomic analysis of ACTTS2 from BAC clone 2H2. BAC clone $2 \mathrm{H} 2$ was selected for further analysis from approximately 1,000 BAC clones from isolate BC-3-5-1-OS2A based on hybridization to the ACTTR PCR probe. The presence of $A C T T$ genes $A C T T 1,2,5$, and $6(20-23)$ in the inserted genomic region in the $\mathrm{BAC}$ clone $2 \mathrm{H} 2$ was verified with $\mathrm{PCR}$. The entire insert of BAC clone $2 \mathrm{H} 2(100 \mathrm{~kb})$ was sequenced to greater than $5 \times$ redundancy by shotgun sequencing using a capillary sequencer. A total of 574,860 bp of sequence data was obtained. Annotation analysis identified 25 contigs of more than $4 \mathrm{~kb}$ with an average redundancy of 4.99 and containing putative ORFs including ACTT1, 2, 5, 6 (20-23), AKT3, and AKTR homologs $(35,36)$, and other putative ORFs encoding a nonribosomal peptide synthetase (NRPS) of 1,218 bp; a HMG-CoA synthase of $1,179 \mathrm{bp}$; an enoyl-reductase of $1,034 \mathrm{bp}$; a monooxygenase of $1,560 \mathrm{bp}$; a polyketide synthase of $7,374 \mathrm{bp}$; an NRPS of $4,833 \mathrm{bp}$; and transposon-like sequences, and several ORFs of unknown function.

Sequence data from the ORF encoding a putative enoyl-reductase of $1,034 \mathrm{bp}$ were used to design gene-specific primers and four primers for $5^{\prime}$ and $3^{\prime}$ RACEs in order to clone the gene from reference isolate $\mathrm{SH} 20$ of the tangerine pathotype of A. alternata. The gene designated as ACTTS2 (accession no. AB516322) is $1,034 \mathrm{bp}$ in length with a predicted 343 amino acid protein (eXtra). BLAST search indicates that ACTTS2 likely encodes an enoyl-reductase and possesses domains similar to the alcohol dehydrogenase GroES-like domain and zinc-binding dehydrogenase domain, and showed high similarity to enoyl-reductases, especially those involved in fungal polyketide biosynthesis, such as $\operatorname{lov} C$ (14).

Presence of multiple ACTTS2 copies in the genome of the tangerine pathotype of A. alternata. The distribution of ACTTS2 in the genomes of seven pathotypes producing different HSTs or nonpathogenic strains of $A$. alternata and a dual pathotype strain BC3-5-1-OS2A was examined by genomic and PFGE Southern blotting (Fig. 1A and B). The distribution of ACTTS2 in the genomes of several different isolates of tangerine pathotype, rough lemon pathotype, and nonpathogenic A. alternata was also examined (Fig. 1C). The ACTTS2 probe only hybridized to the genome of ACT-toxin producers (tangerine pathotype and dualpathotype isolates) (Fig. 1A and $\mathrm{C}$ ), indicating that the presence of ACTTS2 is highly correlated to ACT-toxin production. PFGE and Southern blots demonstrated that ACTTS2 located to a single small chromosome of $1.9 \mathrm{Mb}$ in the tangerine pathotype (SH20) but not to chromosomes from any other A. alternata pathotype (Fig. 1B).

The distribution of ACTTS2 in the genome of isolate SH20 of the tangerine pathotype was further examined (Fig. 2). The ACTTS2 probe detected one fragment when genomic DNA was digested with $E c o$ RI, and $B g l \mathrm{II}$, which have no predicted restriction site within the probe sequence, and two bands were observed upon digestion with EcoRV which has one predicted restriction site within the ACTTS2 probe sequence (Fig. 2). However, multiple bands were observed upon digestion with BamHI, KpnI, $X b a \mathrm{I}$, and $S a c \mathrm{I}$, which have no predicted restriction site within the sequence of the ACTTS2 probe (Fig. 2). These results indicated the presence of multiple ACTTS2 copies with different restriction sites in the flanking DNA or within the ORF region in the genome of isolate $\mathrm{SH} 20$ (Fig. 2).

Targeted gene disruption of ACTTS2 for functional analysis in ACT-toxin biosynthesis. To examine the role of ACTTS 2 in pathogenicity and ACT-toxin production, targeting vector pT7ACTTS2 containing a partial region of ACTTS2 (707 bp) in pT7blue2 (Novagen) was constructed for disruption of ACTTS2 by homologous recombination (Fig. 3A). This vector was cotransformed into the isolate $\mathrm{SH} 20$ of the tangerine pathotype with 


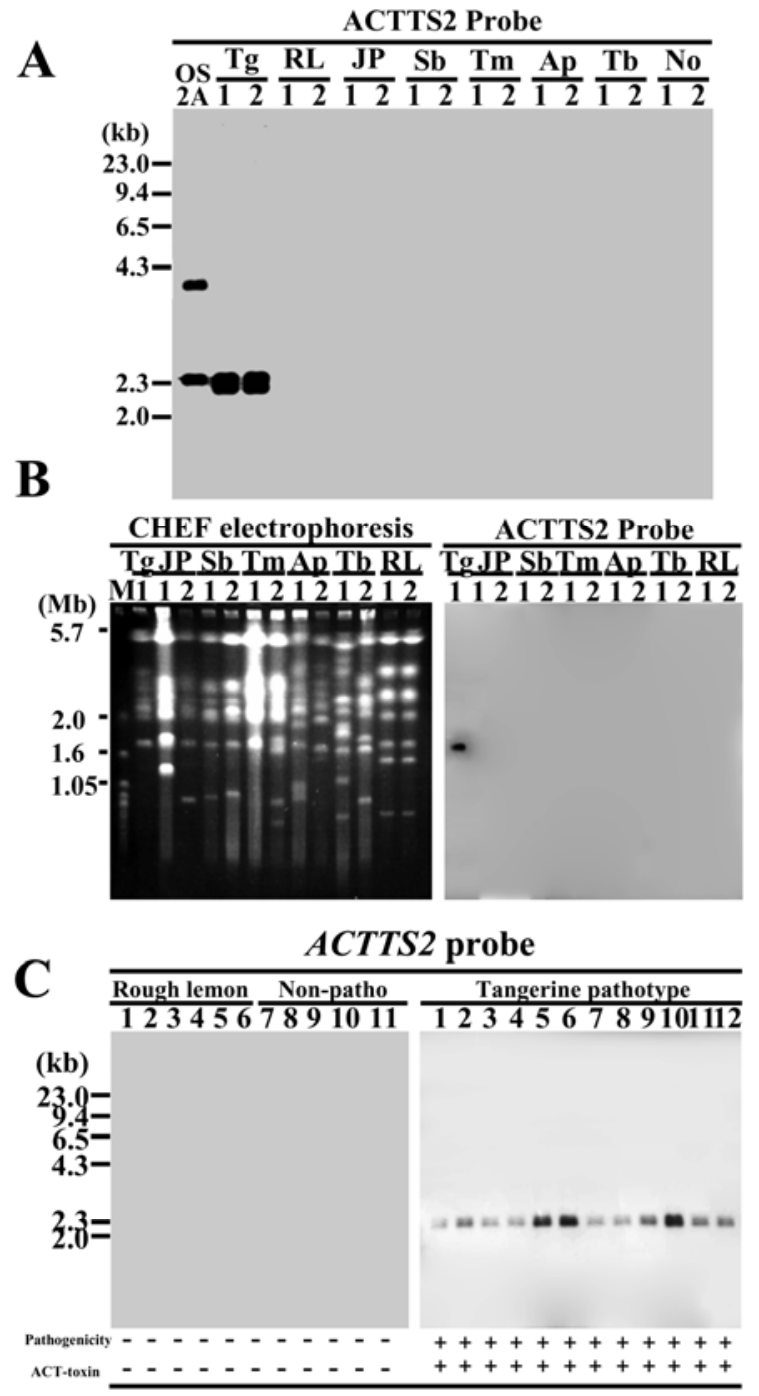

Fig. 1. Distribution of ACTTS2 among different pathotypes and nonpathogenic strains of Alternaria alternata. A, Southern blot analysis of ACTTS2 with seven pathotypes, a nonpathogen, and the dual pathotype isolate BC3-5-1OS2A (OS2A) (20) of A. alternata. Genomic DNA of each fungus was digested with EcoRV. Abbreviations used in panel $\mathbf{A}$ and $\mathbf{B}$ of this figure are as follows: Tg, tangerine pathotype isolates SH11 (lane 1) and SH20 (2); RL, rough lemon pathotype isolates HC1 (1) and HC8 (2); JP, Japanese pear pathotype isolates G31(1) and G90-A2 (2); Sb, strawberry pathotype isolates NAF-3 (1) and NAF-8 (2); Tm, tomato pathotype isolates 91080804 (1) and AL-4 (2); Ap, apple pathotype isolates AM-1 (1) and O-159 (2); Tb, tobacco pathotype isolates No. 122-2 (1) and AT204 (2); and No, nonpathogenic isolates O-94 (1) and HC14 (2). Sizes of marker DNA fragments (HindIIIdigested $\lambda$ DNA) are indicated at left. B, Chromosomal location of ACTTS2 among isolates of seven pathotypes. Intact chromosomes of each isolate were separated with pulse field gel electrophoresis condition in $0.8 \%$ agarose gel (left). Chromosomes were transferred to nylon membrane and hybridized with DIG-labeled ACTTS2 probe (right). Sizes of Saccharomyces cerevisise chromosome size markers are indicated at left. Abbreviations and isolates used in respective lanes were as follows: Tg, isolates SH20 (lane 1); JP, isolates G31(1) and G90-A2 (2); Sb, isolates NAF-3 (1) and NAF-8 (2); Tm, isolates 91080804 (1) and AL-4 (2); Ap, isolates AM-1 (1) and O-159 (2); Tb, isolates No. 122-2 (1) and AT204 (2); and RL, isolates HC1 (1) and HC8 (2). C, Southern blot analysis of the distribution of ACTTS2 among Florida rough lemon pathotype and nonpathogenic strains (left), and tangerine pathotype strains (right). Genomic DNA of each strain was digested with EcoRV. Isolates used in each lane were as follows: 1, HC1; 2, HC7; 3, HC8; 4, BC19; 5, $\mathrm{BC} 27$; 6, BC35; 7, $\mathrm{HC} 14 ; 8, \mathrm{BC} 17$; 9, O-94; 10, BC36; and 11, A. citri (left panel); and 1, SH12; 2, SH13; 3, SH14; 4, SH15; 5, SH18; 6, SH19; 7, SH20; 8, SH21; 9, EV10; 10, EV13; 11, EV14; and 12, EV24 (right panel). Pathogenicity of each strain on Iyokan young leaves and ACT-toxin production are indicated as \pm at bottom of figure. Sizes of marker DNA fragments (HindIIIdigested $\lambda$ DNA) are indicated at left.
pSH75 (15) carrying hph cassette as a selection marker. Screening for reduction in ACT-toxin production by leaf symptom bioassay and for insertion of the vector construct by Southern hybridization identified transformant D6-2, which showed a reduction of the toxin production in culture filtrates and a shift of 7.7-kb ACTTS2 band present in the wild type to $9.4,3.9$, and 2.2-kb bands in the transformant (Fig. 3B), which were the predicted shifts of bands based on the map of ACTTS 2 region, indicating an insertion of the vector construct at the target site (Fig. 3A). The remaining of the 7.7-kb band indicated the presence of multiple copies of ACTTS2. Transcript analysis of ACTTS 2 by RT-PCR with primer set 2H2C7F1 and 2H2C7R2 generated an amplicon of the predicted size (707 bp) from total RNA of wild-type and transformant D6-2, and the products hybridized to the ACTTS2 probe (Fig. 4A). Intensity of the band was reduced but not eliminated in transformant D6-2 compared with that of wild type (Fig. 4A). The PCR reaction without addition of reverse transcriptase did not amplify any product (Fig. 4A). The actin gene, which is known to express constitutively in this fungus (22), was amplified approximately equally to that observed for wild type (Fig. 4A). An approximately $70 \%$ reduction in the peak area of ACT-toxin in HPLC analysis was observed in transformant D6-2 (Fig. 5A). When spores of transformant D6-2 were spray-inoculated on the lower leaf surfaces of susceptible cv. Iyokan, typical leaf spots appeared but disease severity was reduced relative to that caused by the wild-type strain (Fig. 5B).

Use of RNA silencing for functional disruption of ACTTS2. In a previous study, the efficiency of RNA silencing in $A$. alternata was established by knocking down GFP fluorescence in a GFP-overexpressing strain and silencing the multicopy ACTT2 gene in the tangerine pathotype of A. alternata (23). We applied RNA silencing in the current study to knockdown the function of ACTTS2 in the tangerine pathotype of A. alternata. The RNAsilencing vector pASY-ACTTS2 expressing hairpin ACTTS2 RNA, constructed by sense and antisense sequences of ACTTS2 $(1,029 \mathrm{bp})$ in pASY, was cotransformed into the single-copy disruptant D6-2 with pAGY carrying NTPII as the selection marker. A total of 61 transformants were examined for their production of ACT-toxin in the culture filtrates using a leaf

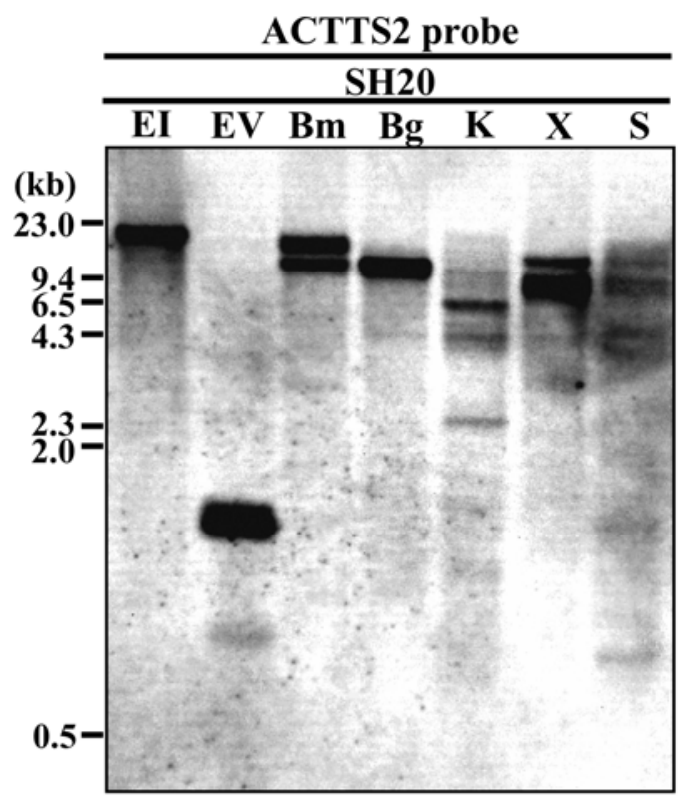

Fig. 2. Southern blot analysis of ACTTS2 in Alternaria alternata tangerine pathotype isolate $\mathrm{SH} 20$ using different restriction enzymes. Genomic DNA of isolate SH20 digested with $E c o$ RI (lane EI), EcoRV (EV), BamHI (Bm), BglII $(\mathrm{Bg}), \mathrm{KpnI}(\mathrm{K}), \mathrm{Xba \textrm {I }}(\mathrm{X})$, and $\mathrm{SacI}(\mathrm{S})$, respectively. Digested DNA was transferred to nylon membrane probed with a DIG-labeled ACTTS2. Sizes of marker DNA fragments (HindIII-digested 1 DNA) are indicated at left. 
necrosis assay. Twelve transformants showing less than $50 \%$ necrosis development than the wild-type $\mathrm{SH} 20$ when inoculated on toxin-sensitive citrus leaves were selected for further study. These transformants were examined for their loss of pathogenicity in a spray-inoculation assay on tangerine leaves and ability to produce ACT-toxin detected by HPLC, and the transformant S6-2-1 were selected. The transformant S6-2-1
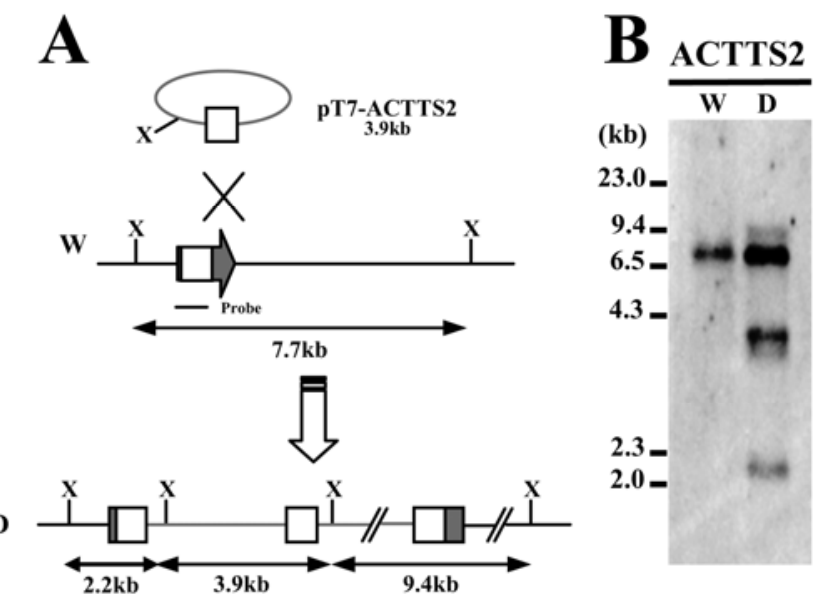

Fig. 3. Targeted gene disruption of ACTTS2 in Alternaria alternata tangerine pathotype isolate $\mathrm{SH} 20$. A, Disruption construct pT7-ACTTS2 and integration pattern in single-copy disruptant D6-2 (W, wild-type; D, D6-2). X signifies XhoI restriction sites. B, Genomic Southern blot of ACTTS2 in wild-type (SH20), single-copy disruptant D6-2. Genomic DNA was digested with XhoI and fractionated in a $0.8 \%$ agarose gel following hybridization with ACTTS 2 probe. Sizes of marker DNA fragments (HindIII-digested $\lambda$ DNA) are indicated at left.
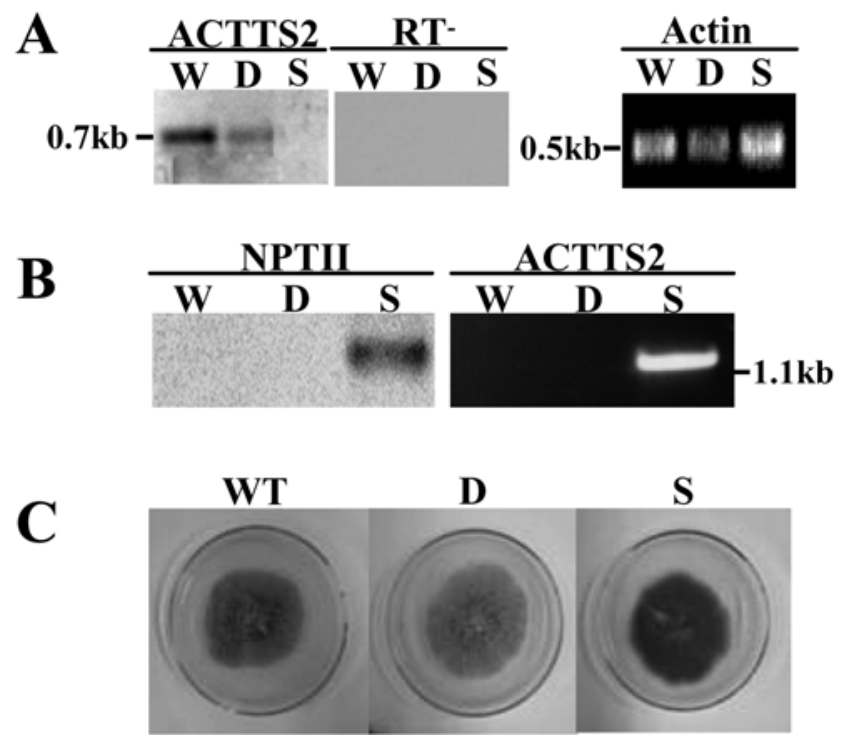

Fig. 4. Reverse transcription-polymerase chain reaction (RT-PCR) and genomic PCR analysis of ACTTS2 disruptant and ACTTS2 RNA-silenced mutant. A, RT-PCR detection of ACTTS2 transcripts in wild-type SH20 (lane W), single-copy ACTTS2 disruptant D6-2 (D) and ACTTS2 RNA-silenced mutant (S), respectively. $\mathrm{RT}^{-}$indicates the PCR without addition of reverse transcriptase. Amplification of actin gene was used as positive control for RTPCR as well as for loading of RNA. B, Insertion analysis of pASY-ACTTS2 by Southern blot of NPTII in wild-type (SH20), single-copy disruptant D6-2, ACTTS2-silencing mutant S6-2-1. Genomic DNA was digested with XhoI and fractionated in a $0.8 \%$ agarose gel following hybridization with NPTII probe. Insertion of the vector was confirmed by genomic PCR of wild-type (SH20), single-copy disruptant D6-2, ACTTS2-silencing mutant S6-2-1 using primer set of 2H2C7RiR4-3NspV and PacCITF1multisite (ACTTS2-PacCIT). C, Growth rate of ACTTS2 in wild-type SH20, single-copy disruptant D6-2, ACTTS2-silencing mutant S6-2-1. carrying pASY-ACTTS2 was resistant to geneticin, NTPII probe hybridized in genomic Southern blot, and PCR using the primer set 2H2C7RiR4-3NspV and PacCITF1multisite indicated insertion of silencing vector pASY-ACTTS2 (Fig. 4B). No ACTTS2 transcript was detected in transformant S6-2-1 by RT-PCR (Fig. 4A). HPLC analysis also did not detect any trace of ACT-toxin in the culture filtrates of S6-2-1 (Fig. 5C). Leaves sprayed with spores of the wild type were covered by necrotic brown lesions 48 $\mathrm{h}$ after inoculation, while those sprayed with spores of S6-2-1 showed no lesions (Fig. 5D). No apparent differences were noticed in growth rate (Fig. 4C), spore formation, and spore germination rates were found among wild-type, single-copy disruptant D6-2, and RNA-silenced transformant S6-2-1.

\section{DISCUSSION}

Genes responsible for ACT-toxin production in the tangerine pathotype of Alternaria alternata identified to date include ACTT1, 2, 3, R, 5, and 6 (20-23). These genes are clustered and located to the smallest chromosomes in the A. alternata genome, generally less than $2 \mathrm{Mb}$ in size. This group of genes has been designated as the ACT-toxin TOX (ACTT) cluster (4,20-23). Only plant-pathogenic A. alternata strains producing HSTs possess these small, dispensable chromosomes responsible for pathogenicity (3,7,20-23). Nonpathogenic strains of Alternaria spp. do not carry these small chromosomes $(3,7,20-23)$. Since these small chromosomes do not appear to carry genes essential for normal growth and reproduction of fungi, their loss has no obvious phenotypic effect on in vitro growth or reproduction $(7,35,36)$. Interestingly, gene clusters responsible for the biosynthesis of HSTs, such as the AKT, AFT, ACTT, ACRT, ALT, and AMT clusters in the Japanese pear, strawberry, tangerine, rough lemon,
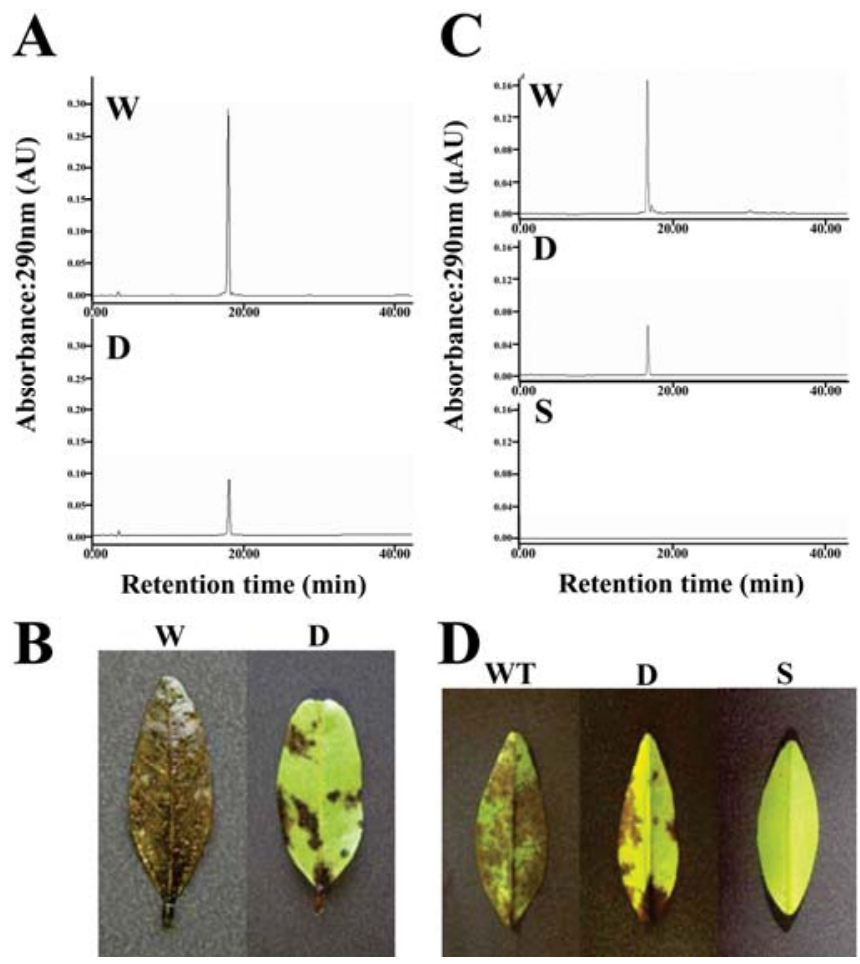

Fig. 5. Effects of single copy disruption and RNA silencing of ACTTS2 on ACT-toxin production and pathogenicity in Alternaria alternata tangerine pathotype isolate $\mathrm{SH} 20$. A and C, HPLC traces of extracts from culture filtrates of ACTTS2 disruptant D6-2 (A) and ACTTS2 RNA silenced mutant S6-2-1 (C). B and D, Pathogenicity tests of mutants using spray-inoculation with conidia of ACTTS2 disruptant D6-2 (B) and ACTTS2 RNA silencing mutant (D) on Iyokan leaves. W represents wild-type isolate SH20, D the single-copy ACTTS2 disruptant D6-2, and S the ACTTS2-silencing mutant, respectively. 
tomato, and apple pathotypes, respectively $(1-4,7,10,11,20-23$, 35,36 ), are all located to small, dispensable chromosomes. In addition, several genes in the $A K T, A F T$, and $A C T T$ clusters are homologous and several genes responsible for production of the common decatrienoic acid moiety of AK-, AF-, and ACT-toxins $(7,20-23,30,35,36)$ are shared among pathotypes. There are only a few examples where genes carried on conditionally dispensable chromosomes in plant-pathogenic fungi have been shown to play a role in pathogenicity. These include Nectria haematococca (37) and several pathotypes of HST-producing A. alternata $(1-4,7$, $10,11,20-23,35,36)$. The only apparent difference between HSTproducing strains of A. alternata and saprophytic strains is the presence or absence of small, dispensable chromosomes. Therefore, more extensive study of these chromosomes including the ORFs encoded in biosynthesis clusters on the chromosomes as well as genomic comparisons of entire chromosomes and ORFs will be valuable for understanding the evolution of microbial pathogenicity.

In this study, we identified several putative ORFs in a $100-\mathrm{kb}$ clone from the $1.9 \mathrm{Mb}$ chromosome carried by reference tangerine pathotype isolate $\mathrm{SH} 20$. We are currently characterizing the roles of these additional ORFs in ACT-toxin production and pathogenicity, and the data presented here demonstrates the involvement of ACTTS2 encoding an enoyl-reductase in HST production and pathogenicity. ACTTS 2 is only carried by the tangerine pathotype among seven pathotypes of HST-producing A. alternata tested and was not present in any other pathotypes or nonpathogenic strains. Multiple copies of ACTTS2 were found on the $1.9 \mathrm{Mb}$ chromosome, and presence of this gene is correlated with ACT-toxin production and pathogenicity among A. alternata. ACTTS2 is likely an enoyl-reductase because it (i) displays sequence similarity to known enoyl-reductases especially those involved in fungal polyketide biosynthesis such as lovC (14), and (ii) possesses domains similar to the alcohol dehydrogenase GroES-like domain and zinc-binding dehydrogenase. $\operatorname{lov} C$ is one of the biosynthesis genes involved in synthesis of the polyketide lovastatin in Aspergillus terreus (14). The major biosynthetic enzyme for lovastatin is a polyketide synthase (PKS) named as lovastatin nonateride synthase encoded by $\operatorname{lov} B(8,14,34)$. PKSs usually consist of multiple functional domains of acyltransferase domain, $\beta$-ketoacyl synthase domain, $\beta$-ketoacyl reductase domain, dehydratase domain, enoyl-reductase domain, and acyl carrier protein domain $(14,27)$. However, the enoyl-reductase domain is missing in $\operatorname{lov} B$, and the function of $\operatorname{lov} C$ complements the insufficiency to synthesize the full structure of lovastatin together with $\operatorname{lov} B(8,14,34)$. ACT-toxin contains a polyketide component $(17,18)$ and the involvement of a PKS in ACT-toxin biosynthesis is expected. Indeed, a gene, designated as ACTTS3, encoding a PKS of 7,374 bp located in the ACTT cluster was identified by sequence analysis of partial region of ACTTS in the $\mathrm{BAC}$ clone $2 \mathrm{H} 2$, and its role in ACT-toxin biosynthesis was confirmed by targeted disruption (Y. Miyamoto and K. Akimitsu, unpublished data). Interestingly, an enoyl-reductase domain is also missing in ACTTS3. We speculate that the function of ACTTS2 might be to complement this insufficiency in ACTTS3 in the synthesis of the polyketide portion of ACT-toxin, similar to the cooperation of $\operatorname{lov} B$ and $\operatorname{lov} C$ in lovastatin synthesis.

We generated a single-copy disruptant of ACTTS 2 using gene targeted disruption and also a functional disruptant of ACTTS2 using RNA silencing. The ACTTS2-silenced mutant S6-2-1 had no detectable ACTTS2 transcript or ACT-toxin production and was nonpathogenic. Although there are multiple copies of ACTTS2 present in the genome of isolate $\mathrm{SH} 20$ of the tangerine pathotype, RNA silencing appeared to be effective in silencing all copies. RNA silencing was used previously to evaluate the role of ACTT2 which is present in at least five copies in the genome of isolate SH20 (23). The data presented here demonstrate a reduction in toxin production and pathogenicity through both single-copy disruption and RNA silencing, and confirm that ACTTS2 plays an important role in ACT-toxin production as well as pathogenicity in the tangerine pathotype of A. alternata.

The tangerine, Japanese pear, and strawberry pathotypes are interesting models for understanding intraspecific variation in host specificity and the evolution of pathogenicity and host specificity in plant-pathogenic fungi. Although these three pathotypes have markedly different host specificities, their HSTs share a common structural moiety of decatrienoic acid in AK-, AF-, and ACT-toxins and homologous genes responsible for the biosynthesis of this moiety exist in genomes of these three distinct pathotypes $(7,20-23,30,35,36)$. ACTTS2 present only in the genome of the tangerine pathotype because the gene is responsible for the biosynthesis of polyketide moiety which is the unique structure in ACT-toxin and not in the structures of AK- and AFtoxins $(4,18,24,25)$. Sequence comparisons of the toxin biosynthesis clusters in these pathotypes as well as comparisons of entire genomes of these fungi should prove fruitful in determining the evolutionary history and trajectories of these different $A$. alternata pathotypes.

\section{ACKNOWLEDGMENTS}

We thank L. W. Timmer for providing strains of A. alternata from Florida and M. Kodama and H. Otani, Tottori University, for valuable discussions and for providing strain O-94. This work was supported by grants for scientific research on priority area (S) from Ministry of Education, Culture, Sports, Science, and Technology of Japan; Precursory Research for Embryonic Science and Technology from Japan Science and Technology Agency.

\section{LITERATURE CITED}

1. Akamatsu, H., Itoh, Y., Kodama, M., Otani, H., and Kohmoto, K. 1997. AAL-toxin-deficient mutants of Alternaria alternata tomato pathotype by restriction enzyme-mediated integration. Phytopathology 87:967-972.

2. Akamatsu, H., Otani, H., and Kodama, M. 2003. Characterization of a gene cluster for host-specific AAL-toxin biosynthesis in the tomato pathotype of Alternaria alternata. Fungal Genet. Newsl. 50:355.

3. Akamatsu, H., Taga, M., Todama, M., Johnson, R., Otani, H., and Kohmoto, K. 1999. Molecular karyotypes for Alternaria plant pathogens known to produce host-specific toxins. Curr. Genet. 35:647-656.

4. Akimitsu, K., Peever, T. L., and Timmer, L. W. 2003. Molecular, ecological and evolutionary approaches to understanding Alternaria diseases of citrus. Mol. Plant Pathol. 4:435-446.

5. Finn, R. D., Tate, J., Mistry, J., Coggill, P. C., Sammut, J. S., Hotz, H. R., Ceric, G., Forslund, K., Eddy, S. R., Sonnhammer, E. L., and Bateman, A. 2008. The Pfam protein families database. Nucleic Acids Res. 36:D281D288.

6. Harimoto, T., Hatta, R., Kodama, M., Yamamoto, M., Otani, H., and Tsuge, T. 2007. Expression profiles of genes encoded by the supernumerary chromosome controlling AM-toxin biosynthesis and pathogenicity in the apple pathotype of Alternaria alternata. Mol. PlantMicrobe Interact. 12:1463-1476.

7. Hatta, R., Ito, K., Hosaki, Y., Tanaka, T., Tanaka, A., Yamamoto, M., Akimitsu, K., and Tsuge, K. 2002. A conditionally dispensable chromosome controls host-specific pathogenicity in the fungal plant pathogen Alternaria alternata. Genetics 161:59-70.

8. Hutchinson, C. R., Kennedy, J., Park, C., Kendrew, S., Auclair, K., and Vederas, J. 2000. Aspects of the biosynthesis of non-aromatic fungal polyketides by iterative polyketide synthases. Antonie van Leeuwenhoek 78:287-295

9. Isshiki, A., Akimitsu, K., Yamamoto, M., and Yamamoto, H. 2001. Endopolygalacturonase is essential for citrus black rot caused by Alternaria citri but not brown spot caused by Alternaria alternata. Mol. PlantMicrobe Interact. 14:749-757.

10. Ito, K., Tanaka, A., Hatta, R., Yamamoto, M., Akimitsu, K., and Tsuge, T. 2004. Dissection of the host range of the fungal plant pathogen Alternaria alternata by modification of secondary metabolism. Mol. Microbiol. 52:399-411.

11. Johnson, R. D., Johnson, L., Itoh, Y., Kodama, M., Otani, H., and Kohmoto, K. 2000. Cloning and characterization of a cyclic peptide synthetase gene from Alternaria alternata apple pathotype whose product is involved in AM-toxin synthesis and pathogenicity. Mol. Plant-Microbe Interact. 13:742-753. 
12. Katoh, H., Isshiki, A., Masunaka, A., Yamamoto, H., and Akimitsu, K. 2006. A virulence-reducing mutation in the postharvest citrus pathogen Alternaria citri. Phytopathology 96:934-940.

13. Katoh, H., Nalumpang, S., Yamamoto, H., and Akimitsu, K. 2007. Overexpression of citrus polygalacturonase-inhibiting protein in citrus black rot pathogen Alternaria citri. J. Plant Physiol. 164:527-535.

14. Kennedy, J., Auclair, K., Kendrew, S. G., Perk, C., Vederas, J. C., and Hutchinson, C. R. 1999. Modulation of polyketide synthase activity by accessory proteins during lovastation biosynthesis. Science 284:13681372.

15. Kimura, N., and Tsuge, T. 1993. Gene cluster involved in melanin biosynthesis of the filamentous fungus Alternaria alternata. J. Bacteriol. 175:4427-4435.

16. Kohmoto, K., Akimitsu, K., and Otani, H. 1991. Correlation of resistance and susceptibility of citrus to Alternaria alternata with sensitivity to hostspecific toxins. Phytopathology 81:719-722.

17. Kohmoto, K., Itoh, Y., Shimomura, N., Kondoh, Y., Otani, H., Kodama, M., Nishimura, S., and Nakatsuka, S. 1993. Isolation and biological activities of two host-specific toxins from the tangerine pathotype of Alternaria alternata. Phytopathology 83:495-502.

18. Kohmoto, K., and Otani, H. 1991. Host recognition by toxigenic plant pathogens. Experientia 47:755-764.

19. Kohmoto, K., Scheffer, R. P., and Whiteside, J. O. 1979. Host-selective toxins from Alternaria citri. Phytopathology 69:667-671.

20. Masunaka, A., Ohtani, K., Peever, T. L., Timmer, L. W., Tsuge, T., Yamamoto, M., Yamamoto, H., and Akimitsu, K. 2005. An isolate that is pathogenic to both tangerines and rough lemon and produces two hostselective toxins, ACT- and ACR-toxins. Phytopathology 95:241-247.

21. Masunaka, A., Tanaka, A., Tsuge, T., Peever, T. L., Timmer, L. W., Yamamoto, M., Yamamoto, H., and Akimitsu, K. 2000. Distribution and characterization of $A K T$ homologs in the tangerine pathotype of Alternaria alternata. Phytopathology 90:762-768.

22. Miyamoto, Y., Ishii, Y., Honda, A., Masunaka, A., Tsuge, T., Yamamoto, M., Ohtani, K., Fukumoto, T., Gomi, K., Peever, T. L., and Akimitsu, K. 2009. Function of genes encoding acyl-CoA synthetase and enoyl-CoA hydratase for host-selective act-toxin biosynthesis in the tangerine pathotype of Alternaria alternata. Phytopathology 99:369-377.

23. Miyamoto, Y., Masunaka, A., Tsuge, T., Yamamoto, M., Ohtani, K., Fukumoto, T., Gomi, K., Peever, T. L., and Akimitsu, K. 2008. Functional analysis of a multicopy host-selective ACT-toxin biosynthesis gene in the tangerine pathotype of Alternaria alternata using RNA silencing. Mol. Plant-Microbe Interact. 21:1591-1599.

24. Nakashima, T., Ueno, T., Fukami, H., Taga, T., Masuda, H., Osaki, K., Otani, H., Kohmoto, K., and Nishimura, S. 1985. Isolation and structure of AK-toxin I and II, host specific phytotoxic metabolites produced by Alternaria alternata Japanese pear pathotype. Agric. Biol. Chem. 49:807815 .

25. Nakatsuka, S., Ueda, K., Goto, T., Yamamoto, M., Nishimura, S., and
Kohmoto, K. 1986. Structure of AF-toxin II, one of the host-specific toxins produced by Alternaria alternata strawberry pathotype. Tetrahedron Lett. 27:2753-2756.

26. Namiki, F., Matsunaga, M., Okuda, M., Inoue, I., Nishi, K., Fujita, Y., and Tsuge, T. 2001. Mutation of an Arginine biosynthesis gene causes reduced pathogenicity in Fusarium oxysporum f. sp. melonis. Mol. Plant-Microbe Interact. 14:580-584.

27. Nicholson, T., Rudd, B., Dawson, M., Lazarus, C., Simpson, T., and Cox, R. 2001. Design and utility of oligonucleotide gene probes for fungal polyketide synthases. Chem. Biol. 8:157-178.

28. Nishimura, S., and Kohmoto, K. 1983. Host-specific toxins and chemical structures from Alternaria species. Annu. Rev. Phytopathol. 21:87-116.

29. Peever, T. L., Canihos, Y., Olsen, L., Ibanez, A., Liu, Y. C., and Timmer, L. W. 1999. Population genetic structure and host specificity of Alternaria spp. causing brown spot of Minneola tangelo and rough lemon in Florida. Phytopathology 89:851-860.

30. Ruswandi, S., Kitani, K., Akimitsu, K., Tsuge, T., Shiraishi, T., and Yamamoto, M. 2005. Structural analysis of cosmid clone pcAFT-2 carrying AFT10-1 encoding an acyl-CoAdehydrogenase involved in AFtoxin production in the strawberry pathotype of Alternaria alternata. J. Gen. Plant Pathol. 71:107-116.

31. Sambrook, J., and Russell, D. W. 2001. Molecular Cloning: A Laboratory Manual. 3rd ed. Cold Spring Harbor Laboratory, Cold Spring Harbor, NY.

32. Sanger, F., Nicklen, S., and Couldon, A. R. 1977. DNA sequencing with chain-terminating inhibitors. Proc. Natl. Acad. Sci. USA 74:5463-5467.

33. Scheffer, R. P., and Livingston, R. S. 1984. Host-selective toxins and their role in plant diseases. Science 223:17-21.

34. Suzanne, M. M., and Tang, Y. 2007. Biochemical characterization of the minimal polyketide synthase domains in the lovastatin nonaketide synthase LovB. FEBS J. 274:2854-2864.

35. Tanaka, A., Shiotani, H., Yamamoto, M., and Tsuge, T. 1999. Insertional mutagenesis and cloning of the genes required for biosynthesis of the host-specific AK-toxin in the Japanese pear pathotype of Alternaria alternata. Mol. Plant-Microbe Interact. 12:691-702.

36. Tanaka, A., and Tsuge, T. 2000. Structural and functional complexity of the genomic region controlling AK-toxin biosynthesis and pathogenicity in the Japanese pear pathotype of Alternaria alternata. Mol. PlantMicrobe Interact. 13:975-986.

37. VanEtten, H. D., Jorgensen, S., Enkerli, J., and Covert, S. F. 1998. Inducing the loss of conditionally dispensable chromosomes in Nectria haematococca during vegetative growth. Curr. Genet. 33:299-303.

38. Walton, J. D. 1996. Host-selective toxins: Agents of compatibility. Plant Cell 8:1723-1733.

39. Wolpert, T. J., Dunkle, L. D., Ciuffetti, L. M. 2003. Host-selective toxins and avirulence determinants: What's in a name? Annu. Rev. Phytopathol. 40:251-285.

40. Yoder, O. C. 1980. Toxins in pathogenesis. Annu. Rev. Phytopathol. 18:103-129. 